\title{
A Perspectiva dos Nossos Leitores: Destaques do Primeiro Questionário aos Leitores da Acta Médica Portuguesa
}

\author{
The Perspective of Our Readers: Highlights of the First \\ Reader's Survey of Acta Médica Portuguesa
}

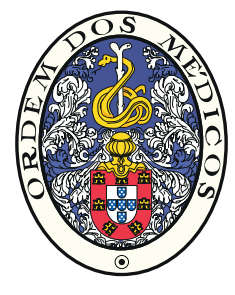

\author{
Duarte BRITO $\triangle^{1,2,3}$, Tiago VILLANUEVA 1 , Carla de SOUSA ${ }^{1}$, Ana Beatriz NUNES ${ }^{1,4}$, Sara DUARTE ${ }^{1,5}$, Miguel REIS ${ }^{1}$ \\ Acta Med Port 2019 Oct;32(10):623-624 - https://doi.org/10.20344/amp.12605
}

Palavras-chave: Escrita Médica; Publicações; Revistas

Keywords: Periodicals; Medical Writing; Publishing

Tal como numa consulta clínica, as boas práticas de gestão e comunicação alertam para a necessidade de envolver o público-alvo no processo de decisão. Ciente da importância de auscultar os leitores e as suas perspetivas, a Acta Médica Portuguesa (AMP) realizou o primeiro questionário à sua comunidade de leitores portugueses, em 40 anos de existência.

O questionário foi enviado por email aos profissionais registados na Ordem dos Médicos e partilhado nas redes sociais da Acta Médica Portuguesa. Entre 15 de maio e 5 de julho foram registadas 470 respostas válidas que permitiram caracterizar o perfil do leitor da Acta Médica Portuguesa, assim como recolher opiniões e sugestões que esperamos integrar nas futuras edições.

A análise destes dados reveste-se de particular importância para o corpo editorial da revista, mas também para eventuais autores que pretendam ir ao encontro das necessidades da comunidade científica. Não havendo diferenças relevantes em relação ao sexo, a maioria dos leitores $(57,2 \%)$ têm uma idade superior a 45 anos. De resto, o facto da Acta Médica Portuguesa ser uma das publicações científicas com maior história em Portugal terá influência nestes resultados. Como seria de esperar, a maioria dos leitores são médicos $(97,2 \%)$. Entre estes, $82,1 \%$ são médicos especialistas, predominando as especialidades de Medicina Geral e Familiar, Medicina Interna, Pediatria, Cirurgia Geral e Anestesiologia.

Enquanto principal revista científica médica generalista em Portugal, a Acta Médica Portuguesa procura diversificar os conteúdos apresentados em cada uma das suas edições. Contudo, este parece ser um fator desmotivador para alguns leitores que preferem a leitura de revistas de especialidade $(34,2 \%)$. A Acta Médica Portuguesa posiciona-se certamente como uma resposta complementar e não como oposição a demais leituras.

Entre o total de leitores inquiridos, $46,5 \%$ dos leitores considera que o conteúdo publicado na Acta Médica
Portuguesa tem sido relevante para a sua prática clínica. Em linha com o enunciado anteriormente, as secções que os leitores consideram mais interessantes são os Artigos originais (70,8\%) e os Artigos de revisão (74,1\%), enquanto as Perspectivas $(14,8 \%)$ e Cartas ao editor $(8,6 \%)$ recoIhem menos atenção (Fig. 1).

Praticamente três quartos dos leitores $(74,1 \%)$ consideram que as secções existentes na Acta Médica Portuguesa têm um número de artigos adequado, havendo sugestões para o aumento de número de artigos em cada uma.

O processo de submissão e publicação de artigos reveste-se de particularidades que a Acta Médica Portuguesa já procurou esclarecer em números anteriores. ${ }^{1,2}$ Cerca de metade dos leitores referem estar satisfeitos com o processo de publicação $(50,3 \%)$ e revisão $(51,0 \%)$, mas salientam a necessidade de melhorar os tempos de resposta, desde a submissão, passando pela revisão até à decisão. Por outro lado, 43,9\% dos respondentes ao questionário já submeteu pelo menos um artigo à Acta Médica Portuguesa. Entre os artigos submetidos, 20,1\% não foram publicados. $\mathrm{Na}$ análise destes dados deve considerar-se um possível viés de resposta, já que leitores que tenham publicado artigos poderão estar mais predispostos para responder ao questionário.

Em relação ao processo de revisão, 18,3\% dos leitores referem já ter sido revisores da Acta Médica Portuguesa, revendo a maioria entre 1 a 2 artigos (43,6\%). É com agrado que verificamos a vontade de um terço dos leitores em se tornarem revisores da revista $(33,2 \%)$. Continuaremos a divulgar esta oportunidade aquando de lançamento de cada edição, através de correio eletrónico.

Vários leitores referem vontade de receber a edição da Acta Médica Portuguesa em formato de papel. Contudo, desde 2004 que a publicação é feita exclusivamente online, tendência que se deverá manter, com a exceção de números comemorativos ou edições para distribuição em eventos científicos. A publicação da AMP apenas em formato digital

\footnotetext{
1. Acta Médica Portuguesa. Ordem dos Médicos. Lisboa. Portugal.

2. Global Health and Tropical Medicine - Instituto de Higiene e Medicina Tropical. Universidade Nova de Lisboa. Lisboa. Portugal.

3. Unidade de Saúde Pública. Agrupamento de Centros de Saúde Lisboa Central. Lisboa. Portugal.

4. Unidade de Saúde Pública. Agrupamento de Centros de Saúde Alentejo Central. Évora. Portugal.

5. Unidade de Saúde Pública. Agrupamento de Centros de Saúde Loures-Odivelas. Santo António dos Cavaleiros. Portugal.

$\square$ Autor correspondente: Duarte Brito. duartebrito6@gmail.com

Recebido: 16 de julho de 2019 - Aceite: 26 de julho de 2019 | Copyright @ Ordem dos Médicos 2019
} 
Secções da Acta Médica Portuguesa com maior interesse $(n=432)$

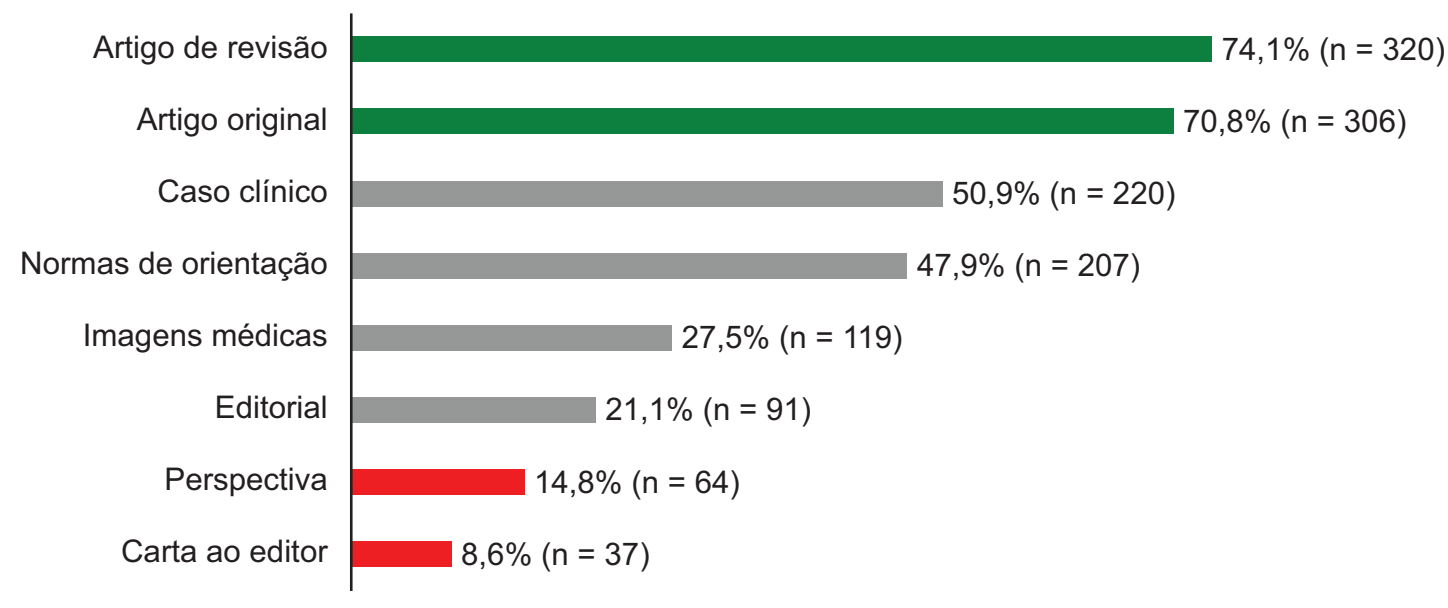

Figure 1 - Secções da Acta Médica Portuguesa com maior interesse para os leitores $(n=432)$

permitiu à Ordem dos Médicos contabilizar uma importante redução das despesas e canalizar o investimento correspondente na criação de uma estrutura profissional e na modernização dos processos editoriais.

Atualmente a tecnologia potencia o uso de diferentes ferramentas para comunicar dentro da comunidade científica, pelo que é essencial compreender como os leitores consultam a revista. Um total de $40,7 \%$ dos nossos leitores utilizam tablets ou telemóveis para consultar artigos publicados na Acta Médica Portuguesa, sendo que $64,8 \%$ o faz exclusivamente em computadores fixos ou portáteis. A maioria dos leitores desconhece a presença da AMP nas redes sociais (Facebook, Twitter e Linkedin). Contudo, vários utilizadores referem não utilizar as redes sociais para fins científicos, uma tendência contrastante com as práticas promovidas em comunicação de ciência.

Um volume significativo de leitores reconhece o esforço de divulgação que tem vindo a ser desenvolvido pela AMP, com $82,6 \%$ dos respondentes a referir que todos os meses são informados da publicação de novas edições, maioritariamente por correio eletrónico $(92,6 \%)$. O fluxo gerado através das redes sociais e aplicações é reduzido $(6,2 \%)$.

Devemos analisar os dados partilhados com a consciência que existirá um viés entre respondedores e não respondedores. Leitores que já tenham publicado artigos na revista, que já tenham sido revisores ou que consultem o seu correio eletrónico mais frequentemente poderão estar mais predispostos a participar neste questionário.

Várias sugestões enumeradas pelos leitores já foram implementadas (como o envio da tabela de conteúdos por

\section{REFERÊNCIAS}

1. Donato H, Marinho RT. Acta Médica Portuguesa and peer-review: quick and brutal! Acta Med Port. 2012;25:261-2.

2. Villanueva T. It is time to move forward. Acta Med Port. 2018;31:5-6.

3. Rawlinson C, Bloom T. New preprint server for medical research. BMJ. email, com hiperligações de acesso a cada um dos artigos) enquanto a eventual introdução de outras será ainda discutida no decorrer deste ano (processo de revisão duplamente cego, estratégias para um processo editorial mais célere, partilha das edições em formato PDF, entre outras). Acreditamos que a curto prazo os tempos de resposta irão melhorar substancialmente pois temos vindo a conseguir progressivamente reduzir o elevado número de artigos que tínhamos sob revisão. Por outro lado, é importante salientar que os autores podem sempre primeiro disponibilizar publicamente os seus artigos originais num preprint server, e só posteriormente submetê-lo à Acta Médica Portuguesa. ${ }^{3}$

Ao longo dos últimos 40 anos, a Acta Médica Portuguesa tem procurado fazer ouvir (em Portugal e cada vez mais também além-fronteiras) a voz de médicos, investigadores e académicos, publicando e indexando os seus trabalhos nas mais importantes bases de dados a nível mundial.

Este objetivo é hoje mais do que nunca enquadrado numa perspetiva de melhoria contínua dos tempos e processos da revisão por pares e de maior exigência de qualidade a nível da informação científica que publicamos. Os nossos processos editoriais estão neste momento alinhados com as melhores práticas editoriais internacionais ${ }^{4}$ - por exemplo, praticamente todos os artigos originais em revisão por pares são submetidos também a revisão estatística.

Neste contexto, esperamos que os resultados que agora partilhamos possam ajudar potenciais autores a adequarem as suas submissões às preferências da comunidade científica portuguesa.

2019;365:I2301.

4. Recommendations for the Conduct, Reporting, Editing, and Publication of Scholarly Work in Medical Journals. [acedido 2019 jul 19]. Disponível em: http://www.icmje.org/icmje-recommendations.pdf. 